\section{Peritonitis bacteriana espontánea de causa atípica}

\section{Sr. Director:}

La peritonitis bacteriana espontánea (PBE), se define como la infección de líquido ascítico, en ausencia de foco infeccioso abdominal aparente (1). La primera descripción detallada de la entidad se realizó en los años 70 (2). Su diagnóstico se establece a través del análisis del líquido ascítico y recuento de Polimorfonucleares. Los criterios utilizados se hallan definidos por el club internacional de la ascitis (3). Es una de las infecciones más frecuentes en el paciente cirrótico con una prevalencia, que según las series varía entre el 10 y el $30 \%$, representando uno de los factores de mayor morbi-mortalidad en el paciente cirrótico hospitalizado. La infección es habitualmente monomicrobiana siendo los microorganismos implicados que se aislan con mayor frecuencia bacterias gram-negativas (E. coli) y en menor medida gram-positivas (Streptococo). Su tratamiento es estrictamente médico. Hallamos descritos en la literatura diferentes regímenes antibióticos empíricos definidos en base a su eficacia (4).

Presentamos a continuación el caso de un varón de 58 años con cirrosis grado B de Child de etiología enólica, diagnosticado hace 8 años por criterios clínicos y de imagen. No otros antecedentes de interés. No recibe tratamiento crónico alguno y no cumple la dieta hiposódica. No episodios previos de descompensación hepática. El paciente acude a nuestro centro por cuadro de deposiciones líquidas sin productos patológicos en número de 10 desde hace 5 días más cuadro febril de hasta $38,5^{\circ} \mathrm{C}$.No se aprecia otro foco infeccioso aparente. Se obtienen muestras sanguineas para cultivo. En la exploración abdominal destaca un abdomen distendido, blando a la palpación con leves signos de irritación peritoneal. Se descarta mediante pruebas de imagen perforación de víscera hueca. Se objetiva descompensación de su hepatopatía con ascitis en moderada cuantía de distribución típica según la ecografía, practicandose paracentesis diagnóstica con obtención de muestras para análisis y cultivo en frascos de hemocultivo (BacT/ALERT). El análisis del líquido ascítico reflejaba los siguientes datos: 30.000 leucocitos con $95 \%$ de PMN, glucosa, LDH, amilasa y diferencia sero-ascítica de albúmina en los limites normales. Una vez confirmado el diagnostico de PBE se inicia terapia antibiótica empírica endovenosa con cefotaxima $2 \mathrm{~g} / 8 \mathrm{~h}$. En los días siguientes el cuadro clínico se agrava con importante deterioro del estado general; el cultivo obtenido anteriormente resulta positivo para Pseudomona aeruginosa en sangre y en líquido ascítico, por lo que se modifica la terapia antibiótica y se inicia tratamiento específico con Ceftazidima $2 \mathrm{~g} / 8 \mathrm{~h}$ (ev).Al cabo de 24 horas el paciente experimenta una importante mejoría con remisión total del cuadro clínico. Tras una semana de tratamiento se obtienen nuevas muestras de líquido ascítico siendo negativo el cultivo del mismo. Tras un año de control el paciente permanece asintomático.

El interés de este caso radica en lo atípico del germen causal; en la literatura se hallan descritos casos esporádicos, habitualmente en enfermos cirróticos avanzados con grado $\mathrm{C}$ de Child y siempre con antecedentes de exploraciones invasivas, tales como endoscopias, que se suponen implicadas en el mecanismo patogénico del proceso (5). En los antecedentes de este paciente no se encuentra manipulación invasiva alguna en los seis meses precedentes. No hallamos descrito otro caso similar con estas características.

Los tratamientos antibióticos empíricos usados en la actualidad cubren hasta en un 90-95\% el espectro bacteriano en la PBE. En el caso que presentamos el microorganismo causal era resistente a la terapia convencional, es por ello que su aislamiento resultó de especial importancia para el inicio del tratamiento adecuado. En pacientes con clínica y analítica sugestiva de PBE el cultivo es negativo en un $60 \%$. Se han postulado diversas teorías que tratan de explicar la baja sensibilidad en la detección de patógenos en el líquido ascítico.La baja densidad de microorganismos se cree que es la causa que explicaría este fenómeno. En el presente caso es interesante señalar el incremento que se obtiene en la rentabilidad diagnóstica al inocular líquido ascítico en medios de hemocultivo. El aumento en la sensibilidad de detección de patógenos en líquido ascítico usando esta técnica es de un $30 \%$. Por ello, es recomendable el uso de medios de hemocultivo siempre que se sospeche PBE con el objeto de optimizar el tratamiento antibiótico.

\section{S. Morán Sánchez, R. Baños Madrid ${ }^{1}$, F. Gallardo ${ }^{1}$}

Sección de Aparato Digestivo. Hospital Santa María del Rosell. Cartagena. ${ }^{\text {IS }}$ ervicio de Digestivo. Hospital Universitario Virgen de la Arrixaca. Murcia

1. Rimola A, Navasa M. Infections in liver disease. En: Bircher J, Benhamou JP, McIatyre N, Rizzeto M, Rodés J, editors. Oxford Textbook of clinical Hepatology. $2^{\mathrm{a}}$ ed. Nueva York, Tokio: Oxford University Press; 1999. p. 1861-1876.

2 Conn HO, Fessel JM. Spontaneous bacterial peritonitis in cirrosis: variations on a theme.Medicine (Baltimore) 1971; 50: 161-197.

3. Rimola A, García-Tsao G, Navasa M, Piddock LJ, Planas R, Bernard B, et al. Diagnosis, treatment and prophylasis of spontaneous bacterial peritonitis: a consensus document. J Hepatol 2000; 32: 142-53

4. Navasa M, Casafont F, Clemente G, Guarner C, De la Mata M, Planas $\mathrm{R}$, et al. Consensus on spontaneous bacterial peritonitis in liver cirrhosis: diagnosis, treatment and prophylaxis.Gastroenterol Hepatol 2001; 24: $37-46$

5. Montalvo II, Gil JA, Arenas JI. Spontaneous bacterial peritonitis caused by Pseudomonas Aeruginosa. Gastroenterol Hepatol 1996; 19: 489. 